\title{
Habitat segregation by moose in a boreal forest ecotone*
}

\author{
Brian K. MILLER and John A. LITVAITIS
}

Miller B. K. and Litvaitis J. A. 1992. Habitat segregation by moose in a boreal forest ecotone. Acta theriol. 37: $41-50$.

We examined seasonal home range size and habitat use by sexes of moose Alces alces (Linnaeus, 1758) near the southern edge of this species' geographic range. Home range size did not differ between males and females during any season. The distribution of forage partly explained seasonal habitat use by both sexes. However, sites occupied by males in summer ( 1 June -15 September) and autumn (16 September - 31 December) were at higher elevations, had steeper slopes, and were farther from potential aquatic feeding sites than sites used by females. We suggest that habitat segregation during these seasons was a consequence of differential resource requirements, not active avoidance by either sex. During summer, females occupied lowland sites near forest cuts, presumably because these sites had abundant forage and dense understory cover that concealed their young from predators. Additionally, females utilized roadside salt licks more often than males during summer and autumn. Males occupied upland hardwood stands during summer in an apparent effort to avoid heat stress and maximize forage intake. Habitat characteristics of both sexes were similar during winter when resource needs were probably equivalent, and the quality and distribution of forage were more homogenous.

Wildlife Prog., Dept. of Nat. Resour., Univ. New Hampshire, Durham, New Hampshire 03824 USA

Key words: Alces alces, habitat segregation

\section{Introduction}

Recent studies have identified a pattern of sexual segregation among dimorphic species of ungulates (Bowyer 1984, Clutton-Brock et al. 1987, McCullough et al. 1989, Shank 1982, Staines et al. 1982, Watson and Staines 1978). With few exceptions (Shank 1982), these studies have reported that females occupy areas of higher habitat quality than males. This spatial separation of males and females may be a response to different resource needs (Bowyer 1984), or differential resource use-efficiencies based on sexual dimorphism (Clutton-Brock et al. 1987, Illius and Gordon 1987). Regardless of the cause, an apparent result of habitat partitioning is that the competition among females may have a greater influence on density-dependent changes of an ungulate population than total population size (McCullough 1979).

\footnotetext{
"Paper No. 1718, New Hampshire Agricultural Experiment Station, University of New Hampshire, Durham, NH 03824
} 
Adult moose Alces alces (Linnaeus, 1758), are sexually dimorphic (Franzmann et al. 1978). Therefore, we speculated that this dimorphism would result in sexual segregation. Specifically, we predicted that female moose would occupy smaller seasonal home ranges as a result of occupying more productive sites.

\section{Study area}

Moose were studied in northern New Hampshire, within the township of Pittsburg $\left(45^{\circ} 10^{\circ} \mathrm{N}\right.$, $71^{\circ} 10^{\circ} \mathrm{W}$ ). This region is near the southern edge of the geographic range of moose in North America (Coady 1982). The immediate study area consisted of broad valleys interspersed with mountains and wetlands, with elevations ranging from 396 to $1,112 \mathrm{~m}$. Most of the land was owned by a private timber company and contained an extensive network of logging roads.

Vegetation of this area included components of coniferous forests to the north and hardwood forests to the south (Westveld et al. 1956). Dominant overstory species on poorly-drained sites included spruce (Picea spp.), balsam fir (Abies balsamea), tamarack (Larix laricina) and northern white cedar (Thuja occidentalis). Red spruce (P. rubens) and balsam fir were common on high slopes. Mid-slope areas were dominated by yellow birch (Betula alleghaniensis), sugar maple (Acer saccharum), paper birch (B. papyrifera), aspen (Populus tremuloides), and beech (Fagus grandifolia).

The climate was cool temperate, with an average annual temperature of $3{ }^{\circ} \mathrm{C}$ (National Oceanic and Atmospheric Administration 1987). The mean daily temperature ranged from $-13^{\circ} \mathrm{C}$ in January to $17^{\circ} \mathrm{C}$ in July (National Ocean and Atmospheric Administration 1987). Precipitation was $100 \mathrm{~cm}$ in 1987.

\section{Methods}

\section{Capture and telemetry}

During August-September 1986 and 1987, moose were located at roadsides (Miller 1989) and immobilized with xylazine hydrochloride $(2 \mathrm{mg} / \mathrm{kg}$ estimated body mass) injected by a projectile syringe fired from a capture rifle. Sedated moose were fitted with collar-mounted transmitters, marked with ear tags, and then administered an antagonistic drug (yohimbine hydrochloride, 0.6 $\mathrm{mg} / \mathrm{kg}$ estimated body weight). Each moose was classified as a yearling or adult according to body size (Peterson 1955).

Transmitter-equipped moose were monitored throughout the day, with $90 \%$ of the locations obtained between 0800 and $2400 \mathrm{hrs}$. Moose were located primarily by triangulation using hand-held, three-element yagi antennas (Mech 1983). Approximately 75\% of the locations were estimated using two successive bearings that were obtained within a $5-15$ min period. The angle of intersection ranged from 45 to $135^{\circ}$. Accuracy of this method was evaluated using reference transmitters placed in known locations. The estimated error was $215 \mathrm{~m}(\mathrm{SE}=27.5 \mathrm{~m}, \mathrm{n}=16)$ from the actual location. In addition, wide-ranging moose were located from a fixed-wing aircraft (Mech 1983). Locations that were separated by $>8 \mathrm{hrs}$ were assumed to be independent based on previous research on the movements and activity patterns of moose (Joyal and Scherrer 1978, Risenhoover 1986). All independent locations were plotted to the nearest $100 \mathrm{~m}$ using universal transverse mercator coordinates and were used to estimate seasonal home range size and habitat use.

\section{Home ranges and habitat use}

Seasonal and composite home ranges (minimum convex polygons - Odum and Kuenzler 1955) were estimated using the program HOMERANGE (Samuel et al. 1985). Seasons were delineated as 
summer (1 June - 15 September), autumn (16 September - 31 December), and winter (1 January $31 \mathrm{March}$ ). An insufficient number of locations ( per animal) were obtained during spring (1 April 31 May), preventing estimates of home ranges for that season. Composite home ranges were estimated by combining all seasonal locations (including spring).

The availability and use of major overstory cover types were examined using forest inventory maps. Available cover types included: hardwood ( $>66 \%$ canopy closure in hardwood species), softwood (>66\% softwood), hardwood-softwood mixed (51 - 65\% hardwood), softwood-hardwood mixed (51 $65 \%$ softwood), cut (clearcut or regeneration stands with $\geq 90 \%$ of their stems $<8 \mathrm{~cm} \mathrm{dbh}$ ), wetland (beaver, Castor canadensis, flowages; bogs; lakes; or slow-moving rivers), and other (agriculture, roadsides, gravel pits, meadows).

Forage availability was investigated by counting woody stems $(<8 \mathrm{~cm} \mathrm{dbh})$ in 2 by $2-\mathrm{m}$ plots within five cover types (hardwood, $\mathrm{n}=50$; softwood, $\mathrm{n}=50$; hardwood-softwood, $\mathrm{n}=84$; softwood-hardwood, $n=15$; and cut, $n=100$ - Miller 1989). Within selected forest stands, plots were sampled at $50-\mathrm{m}$ intervals along systematic transects that were separated by $100-\mathrm{m}$. Only species known or reported to be consumed by moose (Ludwig and Bowyer 1985, Peek 1974) were tallied.

To incorporate the inaccuracy of the telemetry system, we examined the area within a $215-\mathrm{m}$ radius of each moose location. The cover type occupied by a moose was considered to be the type that comprised $\geq 50 \%$ of this 15 ha circle. If no type represented $\geq 50 \%$ of the error circle, that location was excluded from the analysis of cover type use ( $16.2 \%$ of all seasonal locations were excluded from the analysis of cover type use). The number of different cover types within the error circle also were recorded. Additional habitat variables sampled at each telemetry location included elevation, distance to potential aquatic feeding site (beaver flowage, lake, or slow moving river), distance to edge (any change in cover type, size class of dominant trees, or canopy closure class - Miller 1989), and slope (\%). Slope and elevation were determined from USGS 15-min topographic maps. All other variables were obtained from the forest inventory maps. These same variables were sampled at random sites $(n=400)$ within a convex polygon formed by connecting the outermost points of all moose locations (Marcum and Loftsgaarden 1980).

Because the distribution of available sodium may influence movements (Best et al. 1978, Fraser et al. 1980) and habitat-use patterns of moose (Joyal and Scherrer 1978), we investigated use of roadside salt licks by transmitter-equipped moose. Roadside licks formed in low-lying areas from the runoff of road salt, and we identified 12 licks along a $25-\mathrm{km}$ section of Route 3 in Pittsburg (Miller 1989). Average sodium concentration in lick water varied from $628 \mathrm{ppm}$ in May to $123 \mathrm{ppm}$ in October (Miller 1989). To examine use, we characterized lick habitat as the area within a $300-\mathrm{m}$ radius of a central site and estimated use by determining the presence or absence of lick habitat within the $215-\mathrm{m}$ radius of each telemetry location.

\section{Statistical analysis}

Seasonal variation of home range sizes within a sex was evaluated using Kruskal-Wallis tests, and similar comparisons between sexes during each season were made using Mann-Whitney tests. Use-availability analyses of cover types and salt lick habitat were performed using the methods described by Neu et al. (1974). Transformations were performed on slope (arcsine), elevation (log base 10 ), distance to aquatic feeding site (log base 10), and distance to edge (log base 10) to improve their normality (Green 1979). Transformed values were used for statistical analysis; however, values reported here are not transformed. Means of seasonal habitat variables at telemetry locations were compared between sexes, and between moose locations and random sites using $t$-tests. One-way analysis of variance was used to compare forage abundance among cover types. The significance of all tests was assigned at the 0.05 probability level. 


\section{Results}

\section{Home range}

Seasonal home ranges were calculated for 11 individuals ( 3 adult males, 2 yearling and 6 adult females) that had $\geq 14$ locations per season (average number of locations/individual: summer $=42$, autumn $=35$, winter $=24$ ) and were monitored for three or more consecutive seasons (Table 1). There was no relationship between seasonal home range size and the number of locations $(r=$ $0.004, p=1.00, \mathrm{n}=41$ ). Home range sizes of males did not differ among seasons (Kruskal-Wallis test: $\chi^{2}=7.615, p=0.55, \mathrm{n}=12$ ), but did vary among females $\left(\chi^{2}\right.$ $=17.38, p=0.001, \mathrm{n}=29$ ). Autumn ranges constituted the largest percentage of the composite home range (males: $\bar{x}=76.3 \%, \mathrm{SE}=5.9, \mathrm{n}=3$; females: $\bar{x}=$ $57.0 \%, \mathrm{SE}=8.7, \mathrm{n}=8$ ) and winter composed the smallest percentage for both sexes (males: $\bar{x}=10.3 \%, \mathrm{SE}=4.5, \mathrm{n}=3$; females: $\bar{x}=3.9 \%, \mathrm{SE}=1.1, \mathrm{n}=8$ ). Home range size did not differ between males and females during any season $(p$ $>0.05$ ).

Table 1. Average seasonal and composite home range sizes $\left(\mathrm{km}^{2}\right)$, standard errors (SE), number of transmitter-equipped individuals monitored $(n)$, and percentage of composite home range occupied by moose in Pittsburg NH.

\begin{tabular}{|c|c|c|c|c|c|c|c|c|}
\hline \multirow{2}{*}{ Season, year } & \multicolumn{4}{|c|}{ Males } & \multicolumn{4}{|c|}{ Females $^{\mathrm{b}}$} \\
\hline & $\bar{x}$ & $\mathrm{SE}$ & $\mathrm{n}$ & $\%$ & $\bar{x}$ & $\mathrm{SE}$ & $\mathrm{n}$ & $\%$ \\
\hline Summer $1987^{a}$ & 41.4 & 12.3 & 3 & 42.6 & 67.3 & 25.5 & 5 & 42.4 \\
\hline Autumn 1987 & 71.4 & 42.0 & 3 & 76.3 & 81.7 & 21.4 & 8 & 57.0 \\
\hline Winter $1987-88$ & 8.3 & 2.1 & 3 & 10.3 & 3.9 & 0.9 & 8 & 3.9 \\
\hline Summer 1988 & 26.7 & 10.7 & 3 & 28.7 & 43.3 & 6.7 & 8 & 44.0 \\
\hline Composite & 92.8 & 14.3 & 3 & & 152.9 & 47.1 & 8 & \\
\hline
\end{tabular}

${ }^{\mathrm{a}}$ Summer $=1$ June -15 September, autumn $=16-31$ December, winter $=1$ January -31 March.

${ }^{b}$ Summer 1987: Three of five females had ad least one calf, summer 1988: seven of eight females had at least one calf.

\section{Habitat use}

The analysis of cover-type use was based on 1,198 locations from 19 moose ( 3 adult males, 6 yearling and 10 adult females). There was no difference in cover-type use among males during the summer of 1987 and the summer of 1988 $\left(\chi^{2}=3.03\right.$, d.f. $\left.=6, p>0.05\right)$, and these data were combined. During both summers, females were designated as with calf, without calf, or status unknown. There was no difference in cover-type use between females with and without calves during $1987\left(\chi^{2}=12.59\right.$, d.f. $\left.=6, p>0.05\right)$; therefore, these data were combined. An inadequate sample size (females without calves: $n=25$ ) prevented a similar analysis for data collected during the summer of 1988. As a result, we combined all locations of females prior to analysis. 


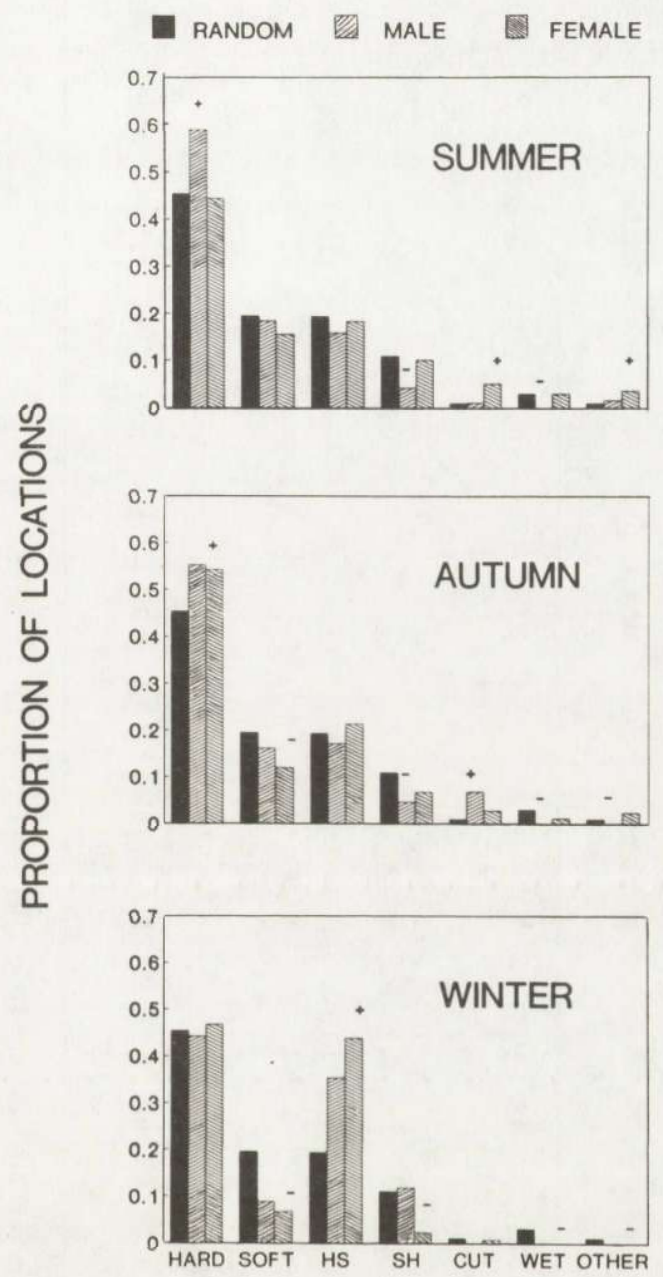

\section{COVER TYPE}

Fig. 1. Use of seven cover types by 19 transmitter-equipped moose ( 3 males, 16 females) in Pittsburg, NH. Civer types included hardwood (H), softwood (S), hardwood-softwood mixed (HS), softwoodhardwod mixed (SH), clearcut or regenerating (CUT), wetland (WET), and other open areas (agriculture, gravel pit, meadow = OTHER). The number of telemetry locations varied by season (summe: males $=190$, females $=503$; autumn: males $=87$, females $=249$; winter: males $=34$, females $=135$ ), and 400 random points were sampled throughout the study area. Use that was greater or less than expected is indicated by + or - , respectively $(p<0.05)$.

Forage abundance varied among the five cover types sampled $(p<0.001)$. Softwcod stands contained fewer stems $(\bar{x}=7,000 / \mathrm{ha}$; $\mathrm{SE}=1,692)$ than hardwood $(\bar{x}=13,400 /$ ha; $\mathrm{SE}=1,790)$, hardwood-softwood mixed $(\bar{x}=13,698 ; \mathrm{SE}=1,234)$, softwond-hardwood mixed $(\bar{x}=16,833 ; \mathrm{SE}=1,867)$, or cuts $(\bar{x}=18,450 ; \mathrm{SE}=1,879$; $p>0.05$ ). 
S u m m e r. Males occupied hardwood stands more, and softwood-hardwood mixed and wetlands less than expected during summer (Fig. 1) $(p<0.05)$. Males also occupied steeper slopes, higher elevation, and were closer to potential aquatic feeding sites than random locations within the study area (Table 2). Use of roadside salt licks by males ( $2.1 \%$ of locations during this season) did not differ from availability ( $2.4 \%$ of study area in salt lick habitat).

Females used cut and other open sites (agriculture, roadside, gravel pit, and meadow) more than expected during summer (Fig. 1). Females also were located in areas having greater diversity of cover types, on less steep slopes, and in closer proximity to potential aquatic feeding sites than random locations $(p<0.05-$ Table 2). Additionally, females visited roadside salt licks more than expected (7.0\% of locations $-p<0.05$ ).

A u t u m n. Males used cut sites more and softwood-hardwood mixed stands, wetlands, and other open areas less than expected during this season, and remained on steeper slopes at higher elevations than random sites. Use of roadside salt licks by males during autumn ( $2.1 \%$ of locations) did not differ from availability.

Females moved into high elevation hardwood stands and used softwoodhardwood stands less than expected $(p<0.05)$ during autumn. Additionally, females remained on less steep slopes and in close proximity to potential aquatic feeding sites. Use of roadside salt licks remained high ( $7.6 \%$ of locations) and was greater than expected $(p<0.05)$.

$\mathrm{W}$ i n $\mathrm{t}$ e $\mathrm{r}$. The limited number of locations obtained on males during this season indicated that they remained on steep slopes at high elevations. Males also used hardwood-softwood mixed stands more during this season, but the small sample size prevented any statistical analysis.

Females moved into hardwood-softwood mixed stands $(p<0.05)$ and used other open areas less than expected $(p<0.05)$. Additionally, females remained at high elevations. We did not record use of roadside salt licks by transmitter-equipped moose during winter.

Table 3. Seasonal comparisons of mean habitat characteristics at male and female moose telemtry locations, Pittsburg, NH.

\begin{tabular}{lccc}
\hline Habitat characteristics & Summer 1987 and 1988 & Autumn 1987 & Winter $1987-88$ \\
\hline Number of cover types & $\mathrm{M}=\mathrm{F}$ & $\mathrm{M}=\mathrm{F}$ & $\mathrm{M}=\mathrm{F}$ \\
Slope & $\mathrm{M}>\mathrm{F}^{*}$ & $\mathrm{M}>\mathrm{F}^{*}$ & $\mathrm{M}=\mathrm{F}$ \\
Elevation & $\mathrm{M}>\mathrm{F}^{*}$ & $\mathrm{M}>\mathrm{F}^{*}$ & $\mathrm{M}=\mathrm{F}$ \\
Distance to aquatic feeding site & $\mathrm{M}>\mathrm{F}^{*}$ & $\mathrm{M}>\mathrm{F}^{*}$ & $\mathrm{M}=\mathrm{F}$ \\
Distance to edge & $\mathrm{M}=\mathrm{F}$ & $\mathrm{M}=\mathrm{F}$ & $\mathrm{M}>\mathrm{F}^{*}$ \\
Use to roadside salt licks & $\mathrm{M}<\mathrm{F}^{*}$ & $\mathrm{M}<\mathrm{F}^{*}$ & $\mathrm{M}=\mathrm{F}$ \\
\hline
\end{tabular}

${ }^{*}$ Characteristics were different between male and female locations $(p<0.05)$. 


\section{Habitat segregation}

Habitat features of male and female locations were different during summer and autumn. Specifically, females were on less steep slopes, at lower elevations, and closer to potential aquatic feeding sites than males (Table 3). Both sexes occupied similar habitat during winter, except that males were closer to a habitat edge than females $(p<0.05)$.

\section{Discussion}

Are females utilizing better habitat than males, or simply different habitat? Our measure of forage distribution indicated that both sexes selected cover types with abundant woody browse. Additionally, home range size did not differ between the sexes during any season, suggesting that males and females occupied habitats of similar quality because range size is dependent on habitat productivity (Harestad and Bunnell 1979, McNab 1963). Relatively equal-sized home ranges also have been observed among male and female moose in regions closer to the core of this species' distribution (Doerr 1983, Hauge and Keith 1981).

Differences in habitat use between sexes of moose during summer and autumn may be a function of differential resource requirements and the different roles of males and females in reproduction. Summer is the season of the greatest nutritional demands of females (Belovsky and Jordan 1978, Schwartz et al. 1984). During this season, females involved in rearing calves may have occupied lowland sites in close proximity to wetlands and cuts for several reasons, including an abundance of forage for the female, and dense understory cover to conceal their calves from predators (Edwards 1983, Leptich 1986). Because these sites contained an abundance of forage and cover, we anticipated that females would restrict their movements while occupying these areas. Demands of lactation for sodium (Belovsky and Jordan 1981, Robbins 1983), however, resulted in females traveling to roadside salt licks, often outside of their usual foraging areas. For example, one female and her calf traveled approximately $7.5 \mathrm{~km}$ from the core of her summer range to a roadside lick in $<8 \mathrm{~h}$ (Miller 1989). Such movements probably resulted in females maintaining relatively large home ranges during this season.

Unlike females, males occupied high elevations with steep slopes during summer. These areas were characterized by extensive hardwood stands and a lack of wetlands. Because moose in our study area are near the southern edge of the species' distribution, we speculate that males, with larger body sizes than females, occupied upland sites to avoid heat stress (Belovsky 1981, Kelsall and Telfer 1974). Leptich (1986) indicated that such a pattern of habitat use may enable males to maximize their energy intake during this season. Although upland hardwood sites may not contain the greatest amount of forage, they were relatively productive, and the closed canopies of these sites may have enabled males to forage for longer periods per day than in more productive, open habitats (i.e., cuts). 
Although our data on habitat use during winter are limited, they indicated that males and females occupied similar sites during this season (Tables 2 and 3). We believe that several factors contributed to this. First, the energy and nutritional requirements of the sexes may be more similar during winter than during summer or autumn (Schwartz et al. 1984). Second, thermal stress among males is less likely in winter, and females may not be selecting sites with dense cover from predators because their calves are increasingly mobile. Finally, habitat heterogeneity may be substantially reduced during winter, especially with respect to forage quality (Renecker and Hudson 1986). Therefore, both sexes may have converged upon similar habitats that fulfilled the needs of this season.

Acknowledgements: We thank K. Klein, E. Orff, and S. Williamson for their efforts in capturing and marking moose. D. Covell, T. Hodgman, R. Hunt, and N. Miller provided valuable field assistance. T. Bowyer, D. Hirth, P. Pekins, M. Pruss, and P. Stapp reviewed early drafts of this report. Financial support was provided by the New Hampshire Fish and Game Department (Pittman-Robertson Proj. No. W-12-R).

\section{References}

Belovsky G. E. 1981. Optimal activity times and habitat choice of moose. Oecologia 48: $22-30$.

Belovsky G. E. and Jordan P. A. 1978. The time-energy budget of a moose. Theor. Pop. Biol. 14: $76-104$.

Belovsky G. E. and Jordan P. A. 1981. Sodium dynamics and adaptation of a moose population. J. Mammal. 62: $613-621$.

Best D. A., Lynch G. M. and Rongstad O. J. 1978. Seasonal activity patterns of moose in the Swan Hiils, Alberta. Proc. N. Amer. Moose Conf. 14: 109 - 125.

Bowyer R. T. 1984. Sexual segregation in southern mule deer. J. Mammal. 65: 410 - 417.

Clutton-Brock T. H., Iason G. R. and Guinness F. E. 1987. Sexual segregation and density-related changes in habitat use in male and female red deer (Cervus elaphus). J. Zool., Lond. 211: $275-289$.

Coady J. W. 1982. Moose. [In: Wild mammals of North America. J. A. Chapman and G. A. Feldhamer, eds]. John Hopkins University Press, Baltimore: 902 - 922.

Doerr J. G. 1983. Home range size, movements and habitat use in two moose, Alces alces, populations in southeastern Alaska. Can. Field-Nat. 97: $79-88$.

Edwards J. 1983. Diet shifts in moose due to predator avoidance. Oecologia 60: 185 - 189.

Franzmann A. W., LeResche R. E., Rausch R. A. and Oldemeyer J. L. 1978. Alaskan moose measurements and weights and measurement-weight relationships. Can. J. Zool. 56: 298 - 306.

Fraser D., Arthur D., Morton J. K. and Thompson B. K. 1980. Aquatic feeding by moose in a Canadian lake. Hol. Ecol. 3: 218 - 223.

Green R. H. 1979. Sampling design and statistical methods for environmental biologists. John Wiley \& Sons, New York: $1-257$.

Harestad A. S. and Bunnell F. N. 1979. Home range and body weight: a reevaluation. Ecology 60: $389-402$.

Hauge T. M. and Keith L. B. 1981. Dynamics of moose populations in northeastern Alberta. J. Wildl. Manage. 45: 573 - 597.

Illius A. W. and Gordon I. J. 1987. The allometry of food intake in grazing ruminants. J. Anim. Ecol. 56: 989 - 999.

Joyal R. and Scherrer B. 1978. Summer movements and feeding by moose in western Quebec. Can. Field-Nat. 92: $252-258$. 
Kelsall J. P. and Telfer E. S. 1974. Biogeography of moose with particular reference to western North America. Naturaliste Canadien 101: 117 - 130.

Leptich D. J. 1986. Summer habitat selection by moose in northern Maine. M.S. unpublished thesis, University of Maine.

Ludwig H. A. and Bowyer R. T. 1985. Overlap in winter diets of sympatric moose and white-tailed deer in Maine. J. Mammal. 66: 390 - 392.

Marcum C. L. and Loftsgaarden D. O. 1980. A nonmapping technique for studying habitat preferences. J. Wildl. Manage. 44: 963 - 968.

McCullough D. R. 1979. The George Reserve deer herd: population ecology of a $K$-selected species. University of Michigan Press, Ann Arbor: $1-271$.

McCullough D. R., Hirth D. H. and Newhouse S. J. 1989. Resource partitioning between sexes in white-tailed deer. J. Wildl. Manage. 53: 277 - 283.

McNab B. K. 1963. Bioenergetics and home range size. Amer. Nat. 97: 133 - 140.

Mech L. D. 1983. Handbook of animal radio-tracking. University of Minnesota Press, Minneapolis: $1-107$.

Miller B. K. 1989. Seasonal movement patterns and habitat use of moose in northern New Hampshire. M.S. unpublished thesis, University of New Hampshire.

National Oceanic and Atmospheric Administration, 1987. Climatological Data Annual Summary, New England 99: 13 .

Neu C. W., Byers C. R. and Peek J. M. 1974. A technique for analysis of utilization-availability data. J. Wildl. Manage. 38: $541-545$.

Odum E. P. and Kuenzler E. J. 1955. Measurement of territory and home range size in birds. Auk 72: $128-137$.

Peek J. M. 1974. A review of moose food habits studies in North America. Naturaliste Canadian 101: $195-215$.

Peterson R. L. 1955. North American moose. University of Toronto Press, Toronto: $1-280$.

Renecker L. A. and Hudson R. J. 1986. Seasonal foraging rates of free-ranging moose. J. Wildl. Manage. 50: 143 - 147 .

Risenhoover K. L. 1986. Winter activity patterns of moose in Interior Alaska. J. Wildl. Manage. 50: $727-734$.

Robbins C. T. 1983 . Wildlife feeding and nutrition. Academic Press, New York: $1-343$.

Samuel M. D., Pierce D. J., Garton E. O., Nelson L. J. and Dixon K. R. 1985. Users manual for program HOMERANGE. University of Idaho Forest, Wildlife and Range Experiment Station Technical Report 15, Moscow: 1 - 79.

Schwartz C. C., Regelin W. L. and Franzmann A. W. 1984. Seasonal dynamics of food intake in moose. Alces 20: $223-244$.

Shank C. C. 1982. Age-sex differences in the diet of wintering Rocky Mountain bighorn sheep. Ecology 63: $627-633$.

Staines B. W., Crisp J. M. and Parish T. 1982. Differences in the quality of food eaten by red deer (Cervus elaphus) stags and hinds. J. Appl. Ecol. 19: 65 - 77.

Watson A. and Staines B. W. 1978. Differences in the quality of wintering areas used by male and female red deer (Cervus elaphus) in Aberdeenshire. J. Zool., Lond. 186: 544 - 550.

Westveld M. R., Ashman R. I., Baldwin H. I., Holdsworth R. P., Johnson R. S., Lambert J. H., Lutz H. J., Swain L. and Standish M. 1956. Natural forest vegetation zones of New England. J. Forestry 54: $332-338$.

Received 20 October 1991, accepted 14 March 1992. 